\title{
The Impact of Vocal Features on Song Success
}

\author{
Abdullah Ali ${ }^{1}$, Jeanette Azzaretto ${ }^{1}$, and Katie Moltz ${ }^{1}$ \\ ${ }^{1}$ Valley Stream South High School, Valley Stream, NY, USA
}

\section{$\underline{\text { ABSTRACT }}$}

The rise of popular music on a global scale has prompted researchers to predict standard features for creating the next hit songs. Previous studies have explored various acoustical/audio features and their relations to top-charting songs but fail to include the artists' voice in determining popular music patterns. As a result, this study had used a trend analysis to find consistent patterns over the selected period (1980-2019) by analyzing five distinct vocal features: vowel corruption, pitch, intensity, number of pulses, and voicing. Upon analyzation, a general increase in vowel corruption and a formant difference in vowels were observed. A stagnant level in intensity and extreme variation in pitch was also noted. Overall, this study was one of the first to find accurate trends, including vocal features in hit song prediction research. Among various implications, one would be introducing a new area of study regarding singing in contemporary music.

\section{Introduction}

For many, music remains an integral part of daily life and is arguably the sole entity that binds many diverse cultures around the world today. Music has served as a beacon of creativity and expression to millions who feel an inner desire to share their experiences with those in reach. However, as we continue to globalize to a point where even the most remote countries are exposed to modern advancements, popular music is no exception. Thus, the global music market was created. Previously, artists released music to gain popularity in their respective countries. However, now that music is distributed worldwide, artists now seek the approval of a global audience. As more artists begin to top popular music charts around the world, it begs the question of how some achieve top spots while others do not. This curiosity has led researchers to analyze specific trends in musical factors used in popular songs to determine what should be included to produce a top-charting song. As of now, studies have investigated the extent of acoustical, instrumental, and lyrical factors. However, much of this research area has ignored the most integral part of song structure, the vocalist.

Singing has long acted as an extension of the human body and has been noted to be an integral part of any song. Since anyone can learn to sing, rather than those who learn instrumentation, it provides a greater sense of being as we continue to find pleasure in hearing ourselves and others sing. Singing requires an individualistic approach and is directly correlated with emotional output making it an invaluable skill to have, especially if a singer has a broad audience (Pfleiderer 2010). Despite this, a significant decline in the use of singing in popular music has created a shift in the music industry. A multitude of songs today showcase complex instrumentation and auditory effects that seem to outshine the individual singing ability of the artist. If this were to continue, it could pose a change in the music industry and the creation of songs, leading to a loss of the art of singing and a new generation of singers who will not have the ability to expand the potential of their voices.

\section{Review of Literature}

In terms of today's musical standards, popularity is determined through songs gaining entrance into popular music charts. These charts are synonymous with factors such as the number of downloads or the number of times the song 
was played. The creation of these charts has prompted an interest in determining the various factors that make it a "hit." So much so that researchers have developed an area of study appropriately dubbed Hit Song Science. The idea of predicting a song's placement on musical charts is known to be a crucial factor before record labels decide to release music, as discussed by François Pachet, a French scientist and the director of the Spotify Creator Technology Research Lab, Hit Song Science is defined as "an emerging field of science that aims at predicting the success of songs before they are released on the market" (Pachet, 2012, p. 305). He emphasizes the significance of this field by mentioning companies such as HSS and PlatiniumBlue. They market their ability to analyze songs and predict how well they will be received on popular charts while selling this information to record labels. However, their method's mechanisms in terms of their analyzation process are unclear and unavailable for public use. Despite this, Pachet insists these companies' mere existence can attest to their reputability to record companies and music labels. In his study, he sought to test how certain audio features such as Generic and Specific audio features could explain the popularity of 32,000 songs taken from various music charts. From the study, Pachet concluded that the general features mentioned cannot analyze the music chosen as they do not give viable results. They additionally do not describe the audio features and their relationship to subjective judgments. He states how the disarranged results found in this study prove that a general approach to Hit Song Science is currently not a viable method for predicting the success of a song. Despite this, he believes that focusing on more specific features for a smaller population, an individual or a community, would yield more favorable results that could provide a glimpse of why we prefer certain songs over others (Pachet 2012). This study solidified itself as a base for various research projects. It defined a field of interest and gave way to the curiosity of Hit Song Science, prompting more researchers to begin their work on this topic.

\section{Machine Learning}

Previous studies have been inclusive of using different machine learning variants along with mathematical models to predict a song's placement on various music charts accurately. Using machine learning, researchers can analyze specific patterns when measuring standard features amongst an assortment of songs well-received by most people. For example, students from Stanford University conducted a study in which they used a Ridge Regression model to verify the accuracy of their algorithm to predict the $(n+1)$ th position of a song on the Billboard Top 100 chart based on the song's previous position or "n." Unlike previous studies that combined various musical and nonmusical factors to predict a song's position, this study focused on data from the Billboard chart itself to craft predictions (Ciblis, Meza \& Ramel, 2015). Using an error function model, they had analyzed around 24,000 songs first using data solely from Billboard and later adding in musical factors. Their results found that their model using only Billboard data was extremely accurate in its prediction, averaging only "4.47 positions away from the actual result" (p. 3). An interesting finding was that adding any musical data into the model skewed the initially favorable results. They confirmed the ability of machine learning to assist in Hit Song Science research focusing more on chart data than musical features. However, a more recent finding offers results that counteract this source. The research used four different machine learning models (Logistic Regression, K-Nearest Neighbours, Gaussian Naive Bayes, and Support Vector Machine) to predict hit songs based on auditory features such as danceability, energy, and loudness (Reiman \& Örnell 2018). This research found that their models could not predict hit songs as the predictions "were no better than random chance" (p. 22). Nevertheless, the Gaussian Naive Bayes model, a function that assumes every variable is independent of each other, had achieved a $60 \%$ prediction rate. However, the researchers did not deem it significant as earlier studies had reported higher rates with the same model. Overall, it seems that machine learning can go either way when testing song predictions. Despite this, Reiman and Örnell suggest that the varying results from machine learning experiments regarding Hit Song Science defining their parameters could explain this. This variation, coupled with a plethora of datasets to implement into various experiments, could explain the accuracy of using machine learning models. What can also be highlighted from these studies is the need to test more features than audio or musical factors and incorporate physical qualities such as popularity or artist labels. 


\section{Musical Analysis}

Literature regarding Hit Song Science has also focused on describing the relationship between distinct musical factors in hit songs. Researchers from the Departments of Mathematics and Statistics from the University of California Irvine analyzed distinct binary variables including timbre, tonality, and mood to assess decadal-trends and correlate these factors with overall success. Over 500,000 songs from the Official Singles Chart released in the UK between 19852015 were examined. It was found that among decadal trends, "happiness" and "brightness" of songs decreased while "sadness" rose substantially. It was also shown that "danceability" and "relaxedness" increased throughout the time interval along with a decrease in the frequency of male singers topping the charts (Interiano et al., 2018). When comparing top songs to average songs, top songs are brighter, have a brighter timbre, are less sad, more party-like, less relaxed, and are more danceable. Top songs are also scarce as, according to their dataset, "less than $4 \%$ of all songs are successful each year" (p. 14). Aside from general trends, when evaluating the success of a song adding in data from previous years did not improve the prediction along with the fact that adding a non-acoustical factor had improved their prediction accuracy: increasing from .74 to around .86. This finding further supports the research findings by Reiman and Örnell as the researchers indicate that the .74 alone proves the need for more nonmusical information to be included in the analysis to obtain a more substantial accuracy rate. Likewise, researcher Yizhao $\mathrm{Ni}$, the senior lecturer in artificial intelligence at the University of Bristol in England, measured 23 acoustical factors on the commercial success of the top and bottom charting songs from 40 UK charts. This study's results included a general trend in the popularity of slower ballad type songs from the 1980s through the 1990s.

In comparison to the modern listener, faster-paced songs are considered more appealing. The most popular songs from every decade analyzed were quite simple when measuring harmonic simplicity and time signature binary. The duration of songs has generally increased along with an increase in loudness of top songs, which Ni cites as a critical factor in distinguishing a hit from a non-hit (Ni, Santos-Rodríguez, Mcvicar \& De Bie, 2011). A study conducted by Dr. David Tough, an Associate Professor of Audio Engineering Technology at Belmont University, combined acoustical factors such as song form, introduction length, and danceability of a song as well as testing nonmusical factors such as song collaboration, presence of Hip-Hop, production of music, and the number of songwriters vs. genre. Tough's results highlighted common trends of songs on the Billboard Hot 100 chart (2014-2015) and suggestions for the creation of future songs. Some suggestions included

- Not stressing over a song duration if it remains under 4 minutes, writing the song at around 120bpm to keep it at a danceable tempo

- Using the name of songs multiple times throughout the track increases the chance of the listener remembering it (Tough 2017).

Since the dataset tested was recent, the suggestions should be adhered to and represent a fundamental approach as both nonmusical and musical factors were tested coinciding with previous works guidelines.

More specific studies homing in on instrumental and lyrical intricacies of hit songs have been investigated as well. Researchers from Oklahoma State University took songs from the years 1955-2015 to determine if lyrical complexity had anything to do with top songs' success. Four main linear regression models were used to determine lyric complexity, but further in the study, these models were subject to change as desired results were not being obtained. After indicating the most successful model, the results revealed that lyrical complexity showed little significance to song success despite the researchers' efforts to find one that best fits the study (Gao, Harden, Hrdinka \& Lin, 2016). Along with this, general trends in instrumentation were investigated in \#1 songs compared to those at the bottom of the chart in the study led by Nunes \& Ordanini (2014). Songs were gathered from the Billboard Hot 100 spanning from the last 55 years and analyzed using a qualitative comparative analysis. During the 1960s and late 2000s, fewer instruments were preferred, while during the mid-1970s, 1980s, and 1990s, the chances of producing a top song increased as did the number of instruments (Nunes et al., 2014). It is also worthy to notice that including 
background vocals is necessary to produce a top song. Without it, songs will inevitably fall to the bottom of the chart, this finding alone can attest to the appreciation for vocals in a song and a need for extended vocal lines.

\section{Singing}

Despite this broad selection of literature, researchers have yet to consider the relationship between the artist's voice and producing popular songs. The mechanics of singing in its most basic understanding involve three essential components: a compressor (breathing apparatus), sound generator (vocal folds), and a resonator (pharynx/mouth cavities). The difference in singing comes from manipulating the vocal tract or the "articulation" of the voice (Sundberg 1987). Using the vocal tract in the contemporary context is further highlighted in "Contemporary Commercial Music: More than One Way to Use the Vocal Tract" by Jeannette LoVetri, a renowned vocal expert in training both musical theatre and famous singers around the world. She discusses how singers will manipulate their vocal tract to satisfy the genre in which they sing. In contemporary Broadway and pop/rock performances, for example, the singers' "larynx may ride up and down, the pharynx may widen and narrow, the tongue may flatten or rise consistently higher in the back of the mouth" (LoVetri, 2002, p. 250). A more prominent study had investigated the vocal techniques used by contemporary commercial singers. Irene Bartlett, a Coordinator of Contemporary Voice and Vocal Pedagogy and Lecturer in Jazz Voice at the Queensland Conservatorium in Griffith University, evaluated contemporary commercial singers (CCM). CCM singers comprise a group of singers who perform at various events as a source of income and often "cover" or replicate famous artists' songs. She mentions in her work that a majority of CCM singers are recognizable by aspects such as "a neutral to higher larynx position, narrowed pharynx, high back of tongue position, and personalized phrasing is accompanied by a speechlike articulation, consonant-driven vocal production with voicing of diphthongs as in speech (rather than pure vowels)" (Bartlett, 2014, p. 31). She also distinguishes classical and contemporary singers' sound as there are significant differences in "laryngeal musculature, acoustic set up, breath management, and most importantly registration" (Bartlett, 2014, p.31). Although this analysis provides an essential insight into contemporary singing, it does not consider specific embellishments that each artist uses to taste. As a result, this study will look to analyze artists with songs in the number one spot on the Billboard Hot 100 chart from the years 1980-2019 and evaluate certain vocal factors (vowel corruption, pitch, and intensity) in their live performances to determine if there exist any prominent trends with the success of their songs.

\section{Methodology}

\section{Song Collection}

Songs were collected by accessing the Billboard Hot 100 chart from Billboard's official website. They were then chosen using the website's timeline feature, which gave access to songs from 1946 to 2019 for this experiment's parameters. The top song for each year was chosen and recorded on a data table, which can be found in Appendix A. From the songs collected, 12 were omitted since they did not meet the parameters for analyzation (the presence of mostly singing in the song). This left 61 songs to be analyzed for vowel corruption, pitch, intensity, number of pulses, and voicing. After this, the songs were found on YouTube, and the audio from the videos was then converted to mp3 files and downloaded for later analyzation. The songs were then put into an Acapella Extractor at acapella-extractor.com, which created a vocal only version of the songs, and downloaded to be later analyzed on a spectrogram.

Before analyzing vowel usage, it is necessary to understand what causes vowel modification. Vowel modification, or vowel shaping, requires certain modifications to the originally spoken vowels so that the word or phrase may be sung more easily. As a result, many professional singers will often modify their vowels when singing to aid them during their performance. Vowel modification leads to different shaping of the vowels which can vary significantly according to voice researcher John Nix, "The amount of modification needed varies with the size of the voice, 
the 'weight' of the voice, the duration of the note being considered, the dynamic level, and how the note in question is approached. Sensitive singers report that the amount of modification they need may vary daily and during the day, depending on how much they have warmed up" (Nix 2004, p. 173). Each vowel also has its distance between the different formats. As described by John Sundberg, formants represent "particular frequencies manifest themselves in the radiated spectrum as peaks in the enve-lope and those peaks are characteristic of particular sounds" (Sundberg 1977, p. 12). Formants can be altered based on manipulating the vocal tract and determining the overall quality of the vowel. To obtain a basis for vowel formants, the program VoceVista was used for its vowel chart as it allows the user to view their singing on a spectrogram to assess pitch accuracy, among other features. Using the vowel chart, approximations in the difference between the first and second vowel formants were obtained, as shown in Table 1. The vowels shown below represent American English Vowels and their estimated difference between the second and first formants.

Table 1. Approximate difference between first and second formants for each indicated vowel.

\begin{tabular}{|c|c|}
\hline Vowels & $\boldsymbol{F 2 - F 1 ~ E s t i m a t i o n ~ ( H z ) ~}$ \\
\hline $\mathrm{i}$ & 1960 \\
\hline $\mathrm{I}$ & 1505 \\
\hline $\mathrm{a}$ & 379 \\
\hline $\mathrm{u}$ & 640 \\
\hline$\varepsilon$ & 1214 \\
\hline$v$ & 568 \\
\hline$\supset$ & 257 \\
\hline
\end{tabular}

After gaining the vowel chart, the songs were then plotted on a spectrogram using the program PRAAT, which allows the user to conduct more in-depth analysis with acoustical factors like the ones being examined in this study: vowel corruption, pitch, and intensity. The image below in Figure 1 provides an example of a visual when examining the song "We Belong Together" by Mariah Carey. The red formant lines, yellow intensity line, and blue pitch line are displayed.

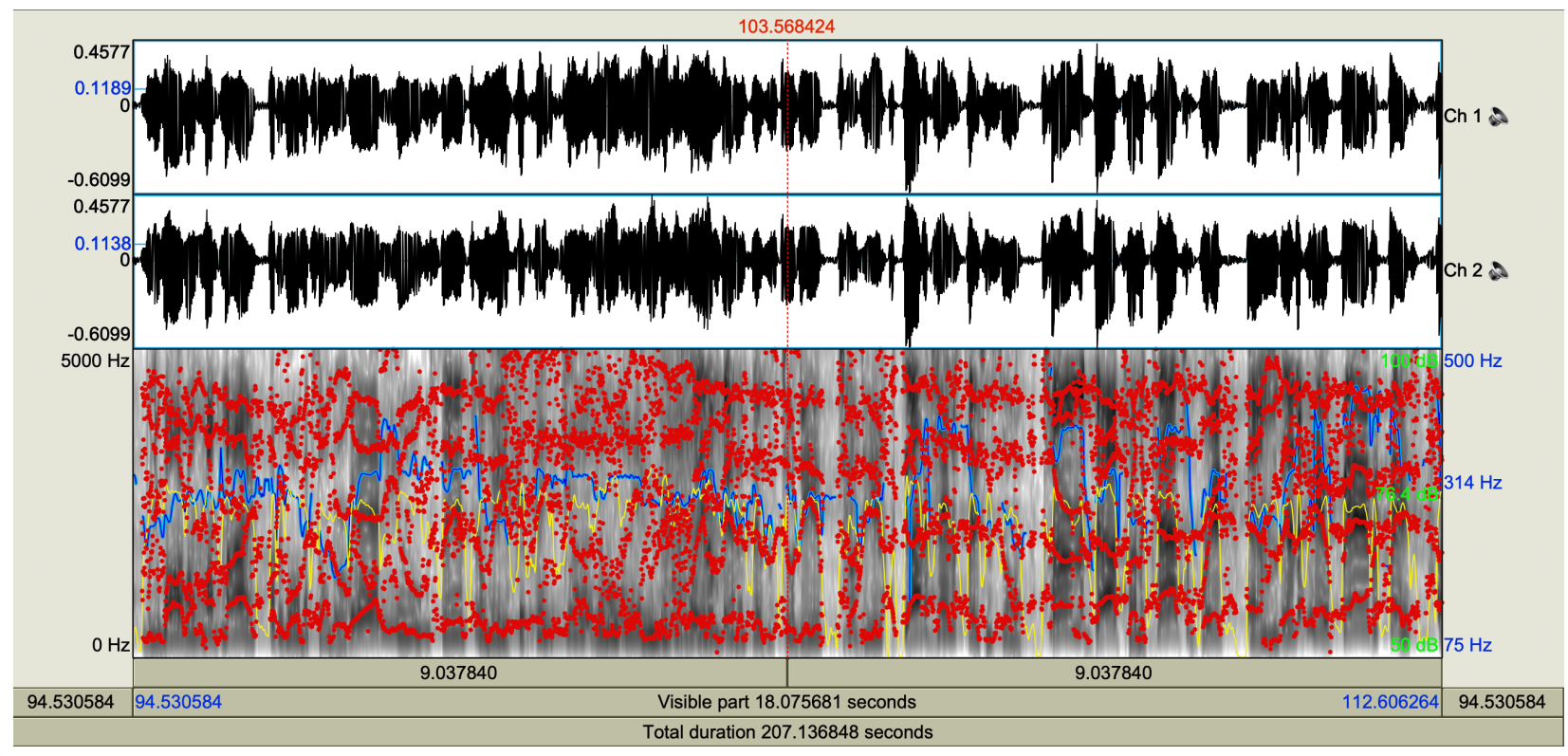

Figure 1. Spectrographic display of $\sim 18.1$ seconds of Mariah Carey's "We Belong Together". 
When measuring vowel corruption for each song, the entire time window was selected, and the average first and second formants were obtained, they were then subtracted to find the difference of the average vowel that was used in the song. The value was then compared to the nearest pure vowel found in Table $\mathbf{1}$ in terms of $\mathrm{Hz}$, and the difference was again found between the pure vowel and the vowel measured from the song, giving the average vowel corruption. The processes for measuring pitch and intensity were not as complicated, as PRAAT can obtain the average pitch and intensity for a selection of a song in the same manner. The fundamental frequency determines pitch (F0) obtained from a selected phrase and measured from the frequency of the short periodic line, measured in Hz. On the other hand, intensity measures the relative loudness of a sound measured in decibels (dB). PRAAT additionally provides a voice reporting feature that includes the number of pulses along with the amount of voicing in a song. Pulses describe the opening and closing of the vocal folds, indicating that a sound is produced while voicing measure the amount of singing in the song expressed as a percentage. In regards to voicing, PRAAT provides a percentage representing the amount of the song that does not contain singing, which is called the "unvoiced" part of the song. These values were obtained and recorded onto separate charts in an online spreadsheet, scatter plot graphs were created based on each element. A linear trend line was added onto the graph along with an accompanying $\mathrm{R}^{2}$ value, defining the amount of data that can be attributed to the trend line drawn.

\section{Results \& Discussion}

The average vowel used in each song is shown in the table below in Table 2. Of the sixty-two songs shown below, 45 songs $(\sim 74 \%)$ had used the " $\varepsilon$ " vowel; 14 songs ( 23\%) had mostly used the "u" vowel, 1 song ( 2\%) had used the "ひ" vowel, and 1 song ( 2\%) had used the "I" vowel.

Table 2. Average vowel used in top songs from each year.

\begin{tabular}{|c|c|}
\hline Year & Vowel Corrupted \\
\hline 1946 & $\varepsilon$ \\
\hline 1947 & $\varepsilon$ \\
\hline 1949 & $\mathrm{u}$ \\
\hline 1950 & $\mathrm{u}$ \\
\hline 1951 & $\varepsilon$ \\
\hline 1953 & $\varepsilon$ \\
\hline 1954 & $\varepsilon$ \\
\hline 1956 & $\varepsilon$ \\
\hline 1957 & $\varepsilon$ \\
\hline 1958 & $\varepsilon$ \\
\hline 1959 & $\mathrm{u}$ \\
\hline 1961 & $\mathrm{I}$ \\
\hline 1962 & $\varepsilon$ \\
\hline 1963 & $\varepsilon$ \\
\hline 1964 & $\mathrm{u}$ \\
\hline 1965 & $\varepsilon$ \\
\hline 1966 & $\varepsilon$ \\
\hline 1967 & $\varepsilon$ \\
\hline 1968 & $\mathrm{u}$ \\
\hline 1969 & $\varepsilon$ \\
\hline 1970 & $\varepsilon$ \\
\hline 1971 & $\mathrm{u}$ \\
\hline
\end{tabular}




\begin{tabular}{|c|c|}
\hline \multicolumn{2}{|c|}{ Table 1 Continued } \\
\hline Year & Vowel Corrupted \\
\hline 1972 & $\varepsilon$ \\
\hline 1973 & $\varepsilon$ \\
\hline 1974 & $\varepsilon$ \\
\hline 1975 & $\mathrm{u}$ \\
\hline 1976 & $\mathrm{u}$ \\
\hline 1977 & $\varepsilon$ \\
\hline 1978 & $\varepsilon$ \\
\hline 1979 & $\varepsilon$ \\
\hline 1980 & $\mathrm{u}$ \\
\hline 1981 & $\varepsilon$ \\
\hline 1982 & $\varepsilon$ \\
\hline 1983 & $\varepsilon$ \\
\hline 1984 & $\mathrm{u}$ \\
\hline 1985 & $\mathrm{u}$ \\
\hline 1986 & $\varepsilon$ \\
\hline 1987 & $\varepsilon$ \\
\hline 1988 & $\varepsilon$ \\
\hline 1989 & $\varepsilon$ \\
\hline 1990 & $\varepsilon$ \\
\hline 1991 & $\varepsilon$ \\
\hline 1992 & $\varepsilon$ \\
\hline 1993 & v \\
\hline 1994 & $\varepsilon$ \\
\hline 1997 & $\mathrm{u}$ \\
\hline 1998 & $\varepsilon$ \\
\hline 1999 & $\mathrm{u}$ \\
\hline 2000 & $\varepsilon$ \\
\hline 2001 & $\varepsilon$ \\
\hline 2002 & $\varepsilon$ \\
\hline 2005 & $\varepsilon$ \\
\hline 2006 & $\mathrm{u}$ \\
\hline 2007 & $\varepsilon$ \\
\hline 2010 & $\varepsilon$ \\
\hline 2011 & $\varepsilon$ \\
\hline 2012 & $\varepsilon$ \\
\hline 2014 & $\varepsilon$ \\
\hline 2015 & $\varepsilon$ \\
\hline 2016 & $\varepsilon$ \\
\hline 2017 & $\varepsilon$ \\
\hline
\end{tabular}

In terms of the vowels used, the formant difference against the songs for each year is displayed in Figure 2. A slight increase can be seen over the entire time range indicated by the trend line. It is also worthy of mention that although the $\mathrm{R}^{2}$ value is low for the charts, this does not necessarily mean that the model is not indicative of the dataset, instead, it is due to the variation in the values measured that lead to increased variation in the results as musical trends 
are generally harder to predict. The increase in the vowel formants should prompt musical producers and companies to have their singers record tracks with vowels that have a more significant difference in their formants (I, $\varepsilon$, or i). Although vowels such as these require a narrower position of the mouth and tongue, there is potential for a greater presence of corruption in these vowels to allow for more effortless singing, which happens to be the case for the results in vowel corruption. As seen in Figure 3, as opposed to the previous figure, the vowel corruption did not always see an upward trend. There was a general decrease in corruption from the early 50s to the mid-70s. After this, a drastic decrease can be seen until the mid-90s. In the period after this to the mid-2000s, a slow increase was evident, which would make sense in today's popular music due to the development of specific genres that include intense manipulation of speaking patterns such as Indie Pop (Jones, Schellenberg \& Gick, 2017).

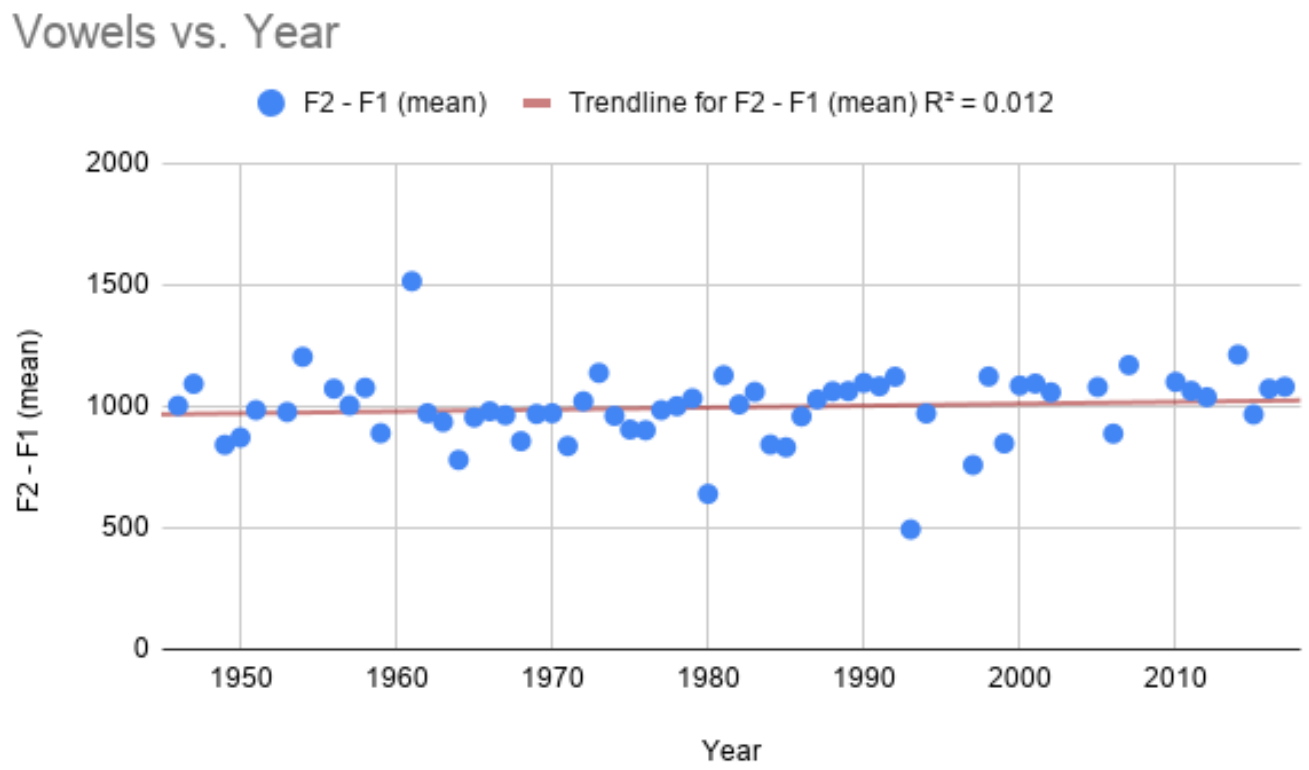

Figure 2. Average vowel used in each song compared to their respective year.

Vowel Corruption (hz) vs. Year

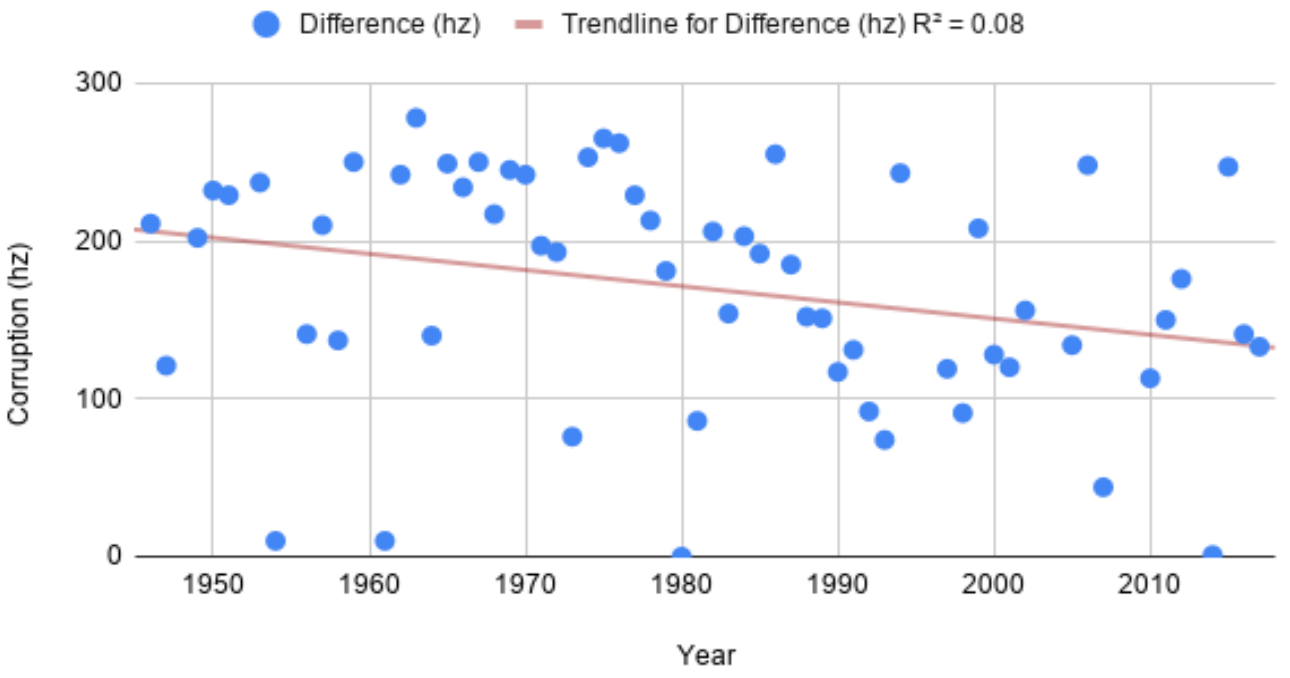

Figure 3. Vowel corruption in top songs compared to their respective years. 
For both pitch and intensity, the trends were similar in that neither had shown a significant increase nor decrease. Figure 4 and Figure 5 show the stagnant trends for pitch and intensity, respectively. An analysis of pitch over the years depicts no visibly coherent pattern as it remains sporadic throughout the entire time interval. Since pitch itself is relative to each singer and can be determined by their voice type, it does not seem ordinary that there is no significant indication of a coherent pattern. On the other hand, when examining the intensity of the songs, they are spaced far less regarding the trend line than the previous figure. There is not much difference in the intensity values obtained as they all center around the $75 \mathrm{~dB}$ mark. The similar intensity values can result from the volume alteration that occurs when mixing a track as the volume of singers and music could be altered to a certain intensity to create an optimally balanced sound. The randomness in pitch can be attributed to each artist's placement and cannot be altered without the use of advanced production that would make the change in sound obvious, which may be why it is avoided.

Avg Pitch (Hz) vs. Year

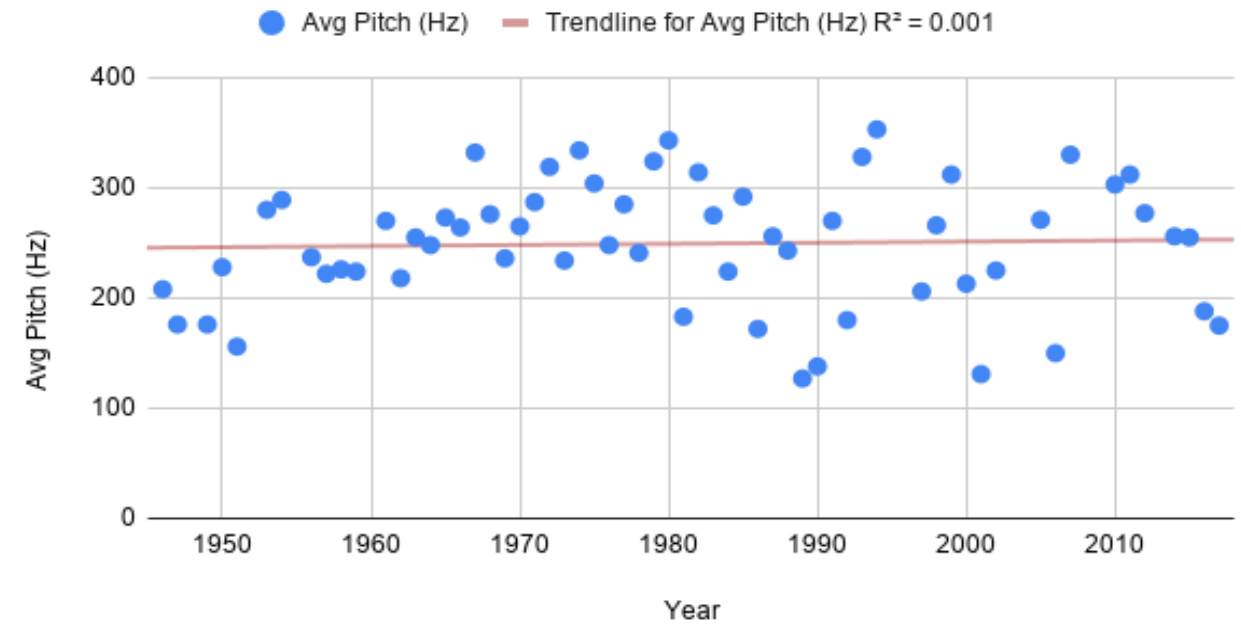

Figure 4. Average pitch found for each song compared to the year.

Intensity (dB) vs. Year

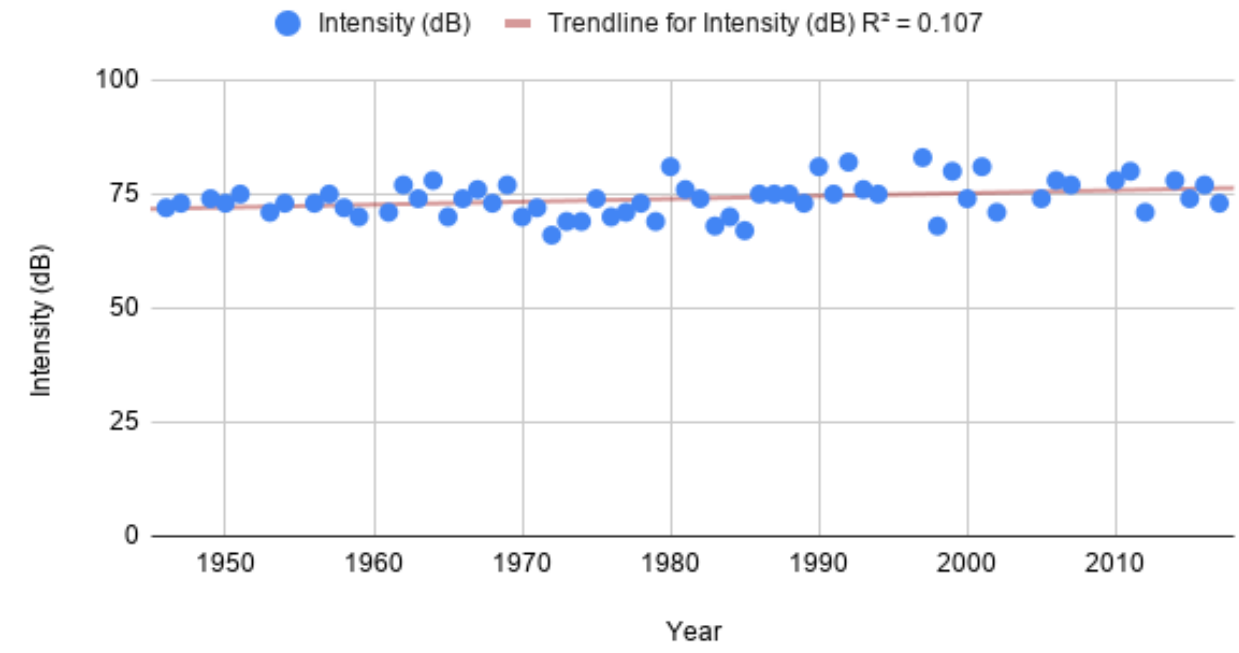

Figure 5. Average intensity calculated for each song compared to each year. 
When looking at the percent unvoiced for each song, there seems to be an apparent decrease over the entire timeline, as shown in Figure 6. This finding is highly noteworthy, especially considering the results of the number of pulses throughout the given timeline. Figure 7 shows that the number of pulses generally increases across the dataset. Essentially, as time progressed, popular songs had a less total singing time but an increased manipulation of vocal folds. Since glottal pulses determine the voice's quality, the results convey the intention of recent singers to vary their singing style. The information supports the initial assumption that recent popular songs contain an array of stylistic choices to enhance the performance of their song.

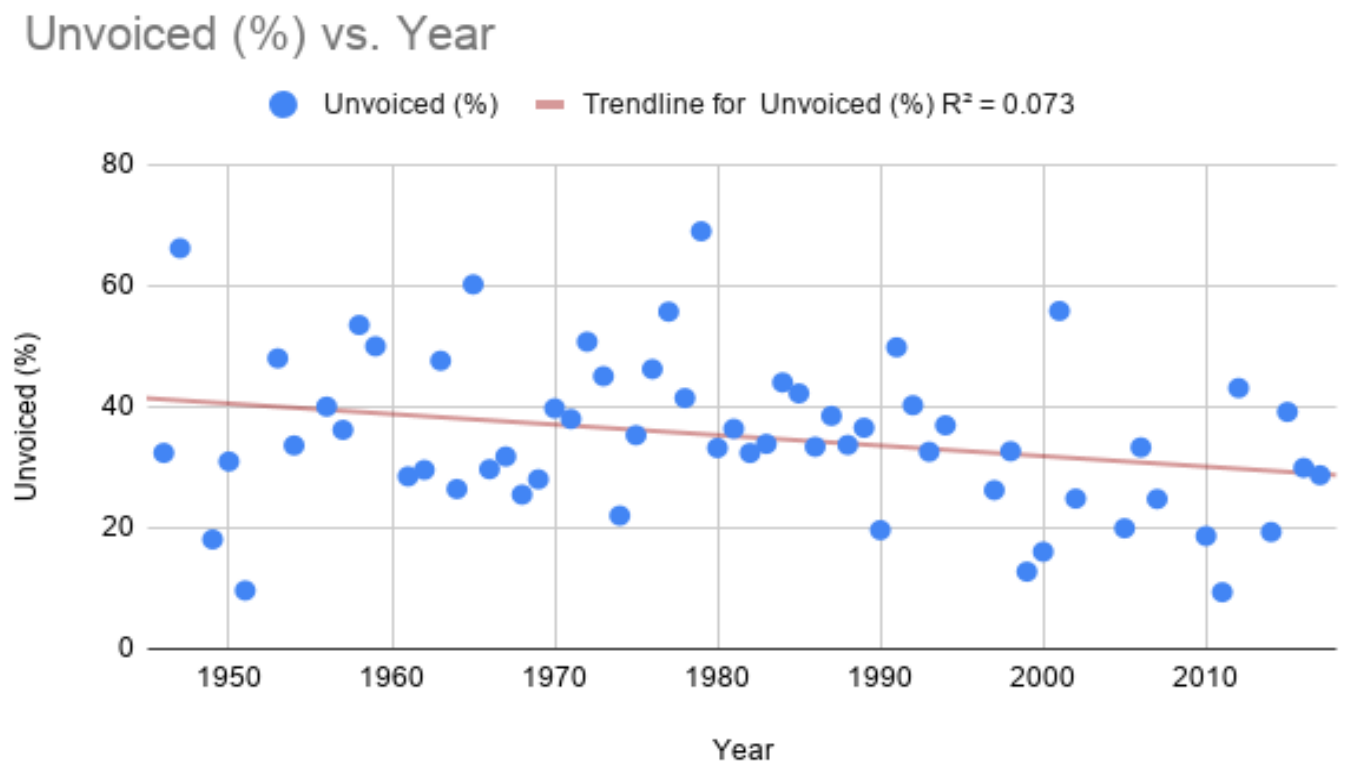

Figure 6. Percent unvoiced for each song respective to their year.

Pulses vs. Year

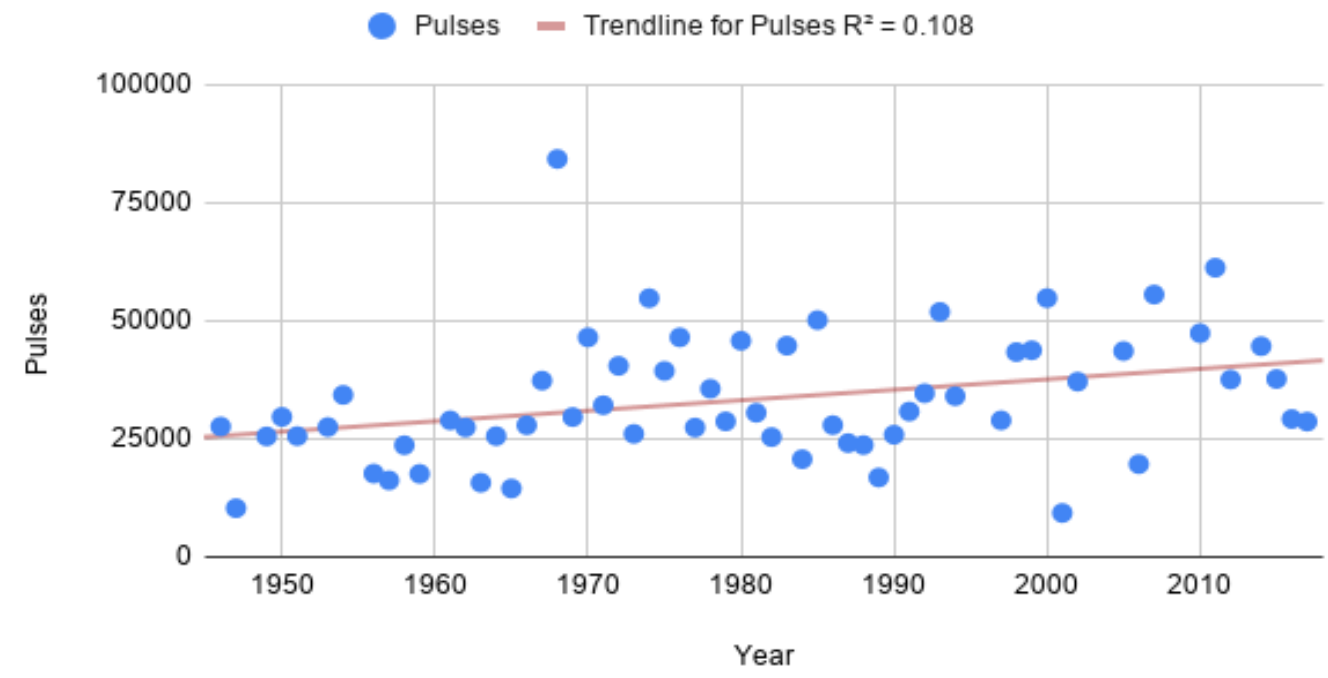

Figure 7. Number of pulses for each song respective to their year. 


\section{Limitations \& Implications}

\section{Limitations}

Conducting the research itself had presented a few limitations that should be addressed if future researchers wish to conduct a similar study. For one, 12 songs were not analyzed, as they did not include mostly singing throughout the song. Additionally, the songs were spread across various genres, requiring different vocal performance methods, as mentioned previously in the Literature Review. Homing in on a specific genre or style of music would look to produce more accurate results when analyzing a common trend. In terms of the songs themselves, each song's audio quality varied due to the extensive timeline chosen for data collection. However, this would be expected as the growth of audio technology has allowed for changes in the music industry in the past decades. It would also be recommended to test more vocal factors such as the use of vibrato or presence of breathiness as they further constitute vocal embellishments that could be worthy of examination.

\section{Implications}

This study has been one of the first to examine trends in certain aspects of the singing voice in the contemporary context. As a result, the conclusions reached during this research prompts various future implications. For one, the area of Hit Song Science could see an increase in development as there is an entirely new research area involving vocal features. Along with this, a shift with more emphasis placed on the artist's voice could be a viable prediction because of the increase in potential data that recording companies will purchase from Hit Song Science researchers. Subsequently, Hit Song Science researchers can capitalize on the results they obtain, leading to an increased sense of legitimacy in these companies and the body of research. A significant change in the music industry could also occur where music producers may adhere more to empirical data to release music rather than the emotive and individual aspects of singing. All in all, leading to a more standardized song production process and increased similarities between popular music across the world.

\section{Conclusion}

To recall, this research sought to determine if there were any trends between vowel corruption, pitch, and intensity in top-charting songs from the years 1946-2019. Despite the limited sample size analyzed in this study, fundamental trends in the vocal factors were examined based on the existing data. The method used throughout the study, albeit new in its inception, could be used by researchers who wish to conduct a similar study. It provides accurate quantitative data that can be compared to a broader set. Analyzing different charts that better represent a more global presence could also be a novel idea to investigate and compare trends in individual countries against one another. It would provide more insight as to what the different areas of the world prefer vocally. Overall, this paper's findings prove a need to conduct more research regarding vocal techniques in popular music that could benefit both the music industry and the area of Hit Song Science.

\section{References}

Bartlett, I. (2014). Reflections on contemporary commercial singing: an insider's perspective. Voice and Speech Review, 8(1), 27-35. Retrieved from https://www.tandfonline.com/doi/pdf/10.1080/23268263.2013.829711

Bhattacharjee, S., Gopal, R. D., Lertwachara, K., Marsden, J. R., \& Telang, R. (2007). The effect of digital sharing technologies on music markets: A survival analysis of albums on ranking charts. Management Science, 53(9), 13591374. Retrieved from https://digitalcommons.calpoly.edu/cgi/viewcontent.cgi?article=1006\&context=mgmt fac 
Cibils, C., Meza, Z., \& Ramel, G. (2015). Predicting a Song's Path through the Billboard Hot 100'. 1-6. Retrieved from http://cs229.stanford.edu/proj2015/012 report.pdf

Dhanaraj, R., \& Logan, B. (2005). Automatic Prediction of Hit Songs. ISMIR, 488-491. Retrieved from http://citeseerx.ist.psu.edu/viewdoc/download?doi=10.1.1.86.4054\&rep=rep1\&type=pdf

Frieler, K., Jakubowski, K., \& Müllensiefen, D. (2015). Is it the song and not the singer? Hit song prediction using structural features of melodies. W., Auhagen, C., Bullerjahn, R. von Georgi, (Eds.), Yearbook of music psychology, 41-54. Retrieved from http://www.doc.gold.ac.uk/ mas03dm/papers/FrielerJakubowskiMullen-

siefen HitSongs 2015.pdf

Gao, Y., Harden, J., Hrdinka, V., \& Linn, C. (2016). Lyric complexity and song popularity: Analysis of lyric composition and relation among billboard top 100 songs. SAS Global Forum, 1-15. Retrieved from https://business.okstate.edu/site-files/archive/docs/analytics/11500-2016.pdf

Henrich, N., d'Alessandro, C., Doval, B., \& Castellengo, M. (2005). Glottal open quotient in singing: Measurements and correlation with laryngeal mechanisms, vocal intensity, and fundamental frequency. The Journal of the Acoustical Society of America, 117(3), 1417-1430. Retrieved from https://hal.archives-ouvertes.fr/hal-00195256/document

Interiano, M., Kazemi, K., Wang, L., Yang, J., Yu, Z., \& Komarova, N. L. (2018). Musical trends and predictability of success in contemporary songs in and out of the top charts. Royal Society open science, 5(5), 171-274. Retrieved from https://royalsocietypublishing.org/doi/pdf/10.1098/rsos.171274

Jones, C., Schellenberg, M., \& Gick, B. (2017). Indie-Pop Voice: How a Pharyngeal/Retracted Articulatory Setting May Be Driving a New Singing Style. Canadian Acoustics, 45(3), 180-181. Retrieved from https://pdfs.semanticscholar.org/db68/5cf736213f2b3787fab34b1117f4f64afaed.pdf

Krumhansl, C. L. (2000). Rhythm and pitch in music cognition. Psychological bulletin, 126(1), 159-179. Retrieved from http://math.jacobs-university.de/oliver/teaching/iub/spring2005/mmm/handouts/rhythm.pdf

LoVetri, J. (2002). Contemporary commercial music: More than one way to use the vocal tract. Journal of Singing, 58(3), 249-252. Retrieved from http://www.vocapedia.info/ Library/JOS files Vocapedia/JOS-058-3-2002-249.pdf

Ni, Y., Santos-Rodriguez, R., Mcvicar, M., \& De Bie, T. (2011). Hit song science once again a science. 4th International Workshop on Machine Learning and Music: Learning from Musical Structure, Sierra Nevada, Spain, 1-2. Retrieved from http://citeseerx.ist.psu.edu/viewdoc/download?doi=10.1.1.412.9732\&rep=rep1\&type=pdf

Nix, J. (2004). Vowel modification revisited. Journal of Singing, 61(2), 173-176. Retrieved from http://www.vocapedia.info/ Library/JOS files Vocapedia/JOS-061-2-2004-173.pdf

Nunes, J. C., \& Ordanini, A. (2014). I like the way it sounds: The influence of instrumentation on a pop song's place in the charts. Musicae Scientiae, 18(4), 392-409. Retrieved from https://msbfile03.usc.edu/digitalmeasures/jnunes/intellcont/Musicae\%20Scientiae-2014-Nunes-1.pdf

Pachet, F., \& Sony, C. S. L. (2012). Hit song science. Music data mining, 305-326. Retrieved from https://csl.sony.fr/wp-content/themes/sony/uploads/pdf/pachet-11a.pdf 
Pfleiderer, M. (2010). Vocal pop pleasures. Theoretical, analytical and empirical approaches to voice and singing in popular music. IASPM@ Journal, 1(1), 1-16. Retrieved from https://scholar.google.com/scholar url?url=http://iaspmjournal.net/index.php/IASPM Journal/article/download/301/547\&hl=en\&sa=T\&oi=gsbgga\&ct=res\&cd=0\&d=15356154570024661920\&ei=AnMjX9jYJIvrmQHli6fYDQ\&scisig=AAGBfm2CGnxGOmJd8SYK8aipJ45Z3 dEQ

Reiman, M., \& Örnell, P. (2018). Predicting Hit Songs with Machine Learning. 1-29. Retrieved from https://www.diva-portal.org/smash/get/diva2:1214146/FULLTEXT01.pdf

Sundberg, J. (1988). Vocal tract resonance in singing. The NATS Journal, 44(4), 11-20. Retrieved from https://www.nats.org/ Library/Kennedy JOS Files 2013/JOS-044-4-1988-011.pdf

Tough, D. (2013). Teaching Modern Production and Songwriting Techniques: What Makes a Hit Song?. MEIEA Journal, 13(1). Retrieved from https://www.davetough.com/images/ToughMEIEA2013.pdf

Tough, D. (2017). An analysis of common songwriting and production practices in 2014-2015 Billboard hot 100 songs. MEIEA Journal, 17(1), 79. Retrieved from https://www.davetough.com/songwritingproductionmeiea2018.pdf 